\title{
IGNITION AND COMBUSTION OF SINGLE SOLID PARTICLES AS NON-ISOTHERMAL METHODS OF CHEMICAL KINETICS
}

\author{
Grigore Ambrosi*, ORCID ID: 0000-0001-7232-2998 \\ Technical University of Moldova, 168 Ștefan cel Mare și Sfânt Blvd., Chisinau, Republic of Moldova \\ *Corresponding author: Grigore Ambrosi, grigore.ambrosi@tran.utm.md
}

Received: 06. 17. 2021

Accepted: 08. 12. 2021

\begin{abstract}
The ignition and combustion of single particles of crystalline boron continue to produce major scientific interest due to the particularities of the process and diversity of potential applications of boron compounds. The full valorization of boron energetic potential is a very current scientific challenge. The objective of the paper is to systematize the methodology for evaluating the kinetic parameters of boron ignition and combustion reactions in various oxidizing gaseous environments. Experimental dependencies between the ignition temperature and the particle size, as well as the combustion time as a function of oxidizing temperature are used for the calculation of the kinetic constants. As a main result, the kinetic parameters of the ignition and combustion reactions of boron in oxygen and water vapor are calculated.
\end{abstract}

Keywords: boron, thermodynamics, reaction, oxidation, heterogeneous, calculation, parameter, experiment.

\section{Introduction}

Initially approached by Wilhelm Nusselt, the issue of ignition and combustion of the solid particle still requires major attention. Despite an impressive amount of relevant information on this topic and the formulation of remarkable theoretical generalizations, currently there is no irrevocable analytical theory, which considers the complexity of physicochemical phenomena specific to heterogeneous ignition and combustion processes. Usually, simplified models of chemical processes are applied or the similarity theory is used.

Chemical kinetics, developed from practical needs to clarify the picture of chemical transformations, especially for the determination of the speed and mechanism of reactions, contributes decisively to the study of ignition and combustion phenomena. Currently, the studies of chemical kinetics are combining two complementary directions, both of them having different paradigms and tasks [1].

The objective of the first direction is to identify the mechanism of the reaction. This objective is achieved by applying the modern methods of stoichiometry, chemical thermodynamics, theory of solid mechanics and theory of activated complex. Thus, the kinetic parameters of the sequence of elementary reactions are calculated theoretically and measured experimentally. The results are mainly of a qualitative nature. Consequently, the 
intermediates and the sequence of transformation of the reactants into products are established [1].

The second direction of research is formal kinetics, which is methodologically analyzed in this paper. It consists in the phenomenological quantitative investigation of complex reactions, with sufficiently precise determination of kinetic parameters. The importance of these studies is growing due to the lack of accurate kinetic information needed in practice for model simulation and process optimization [2, 3].

The processes of ignition and combustion of the boron particle are characterized by a higher level of complexity than in the case of classical solid fuel particles. The main particularity is determined by the existence of the surface oxide layer, formed in the latent phase of the preliminary reaction, which substantially changes the picture of the interaction [2], [4], [8], [9].

The high calorific value and the distinctive physical-mechanical properties of some boron compounds are of increased interest, because these substances are less studied for energetic and technological applications $[3,4,9,10]$.

Until the development of non-isothermal theories in chemical kinetics, the selfheating of the reactant was qualified as an experimental error that deforms the kinetic curves. The theory of thermal explosion cardinally changed the approach to the problem, confirming the opportunity of kinetic study in non-isothermal conditions [2, 4].

The essence of this theoretical realization consists in the fact that the models of nonisothermal phenomena quantitatively relate the measurable characteristics of the processes with the kinetic parameters. If the conditions of chemical transformations are known, the physical parameters of the system being measured, then by solving the inverse problem the kinetic parameters of the chemical reaction can be determined: activation energy $E, \mathrm{~J} \cdot \mathrm{mol}^{-}$ ${ }^{1}$ and the pre-exponential coefficient $k_{0}, \mathrm{~m} \cdot \mathrm{s}^{-1}[2,4,7]$.

The defining characteristics are: the value of the oxidant temperature at ignition place of the sample $\left(T_{g a},{ }^{\circ} \mathrm{K}\right)$, the duration of particle ignition under the respective conditions $\left(t_{a p}, \mathrm{~s}\right)$ and the burning rate of the solid substance $\left(t_{a r}, \mathrm{~s}\right)$. A wide variety of methods for calculating kinetic parameters from experimental ignition and combustion data are currently being developed and applied.

\section{Evaluation of kinetic parameters for the ignition of solid particles}

If the solid substance and the high temperature gaseous oxidant $\left(700-2000^{\circ} \mathrm{K}\right)$ are separated by an oxide film, usually the speed of the chemical interaction is limited by the diffusion of the oxidant through the oxide layer to the reaction surface and depends not only on the temperature and the concentration of the oxidant, but also on the thickness of the increasing layer $[2,4,5,6]$.

Experimentally, different oxidation laws have been established [83]. The main laws states that the speed of the reaction $R_{o x}$ (the rate of increase of the oxide layer) decreases with the increase of the thickness $h$ of the film, inversely proportional to the thickness of the diffusion barrier raised to the power of $n[2,4]$ :

$$
R_{o x}=\rho_{o x} \cdot \frac{d h}{d t}=\frac{C_{o x}^{v}}{h^{n}} \cdot k_{0} \cdot e^{-\frac{E}{R T}}, \mathrm{~mol} \cdot \mathrm{m}^{-2} \cdot \mathrm{s}^{-1}
$$

where: $\rho_{o x}$ is the density of the oxide surface layer $\left(\mathrm{B}_{2} \mathrm{O}_{3}\right), \mathrm{mol} \cdot \mathrm{m}^{-3}$; 
$C_{o x}$ - oxidant concentration in the gaseous environment, $\mathrm{mol} \cdot \mathrm{m}^{-3}$;

$v$ - reaction order for the given oxidant;

$E$ - activation energy of the oxidation reaction in the ignition phase, $\mathrm{J} \cdot \mathrm{mol}^{-1}$;

$k_{0}$ - the pre-exponential coefficient of the oxidation reaction, $\mathrm{m} \cdot \mathrm{s}^{-1}$.

The exponent $n$ defines the relationship between the reaction rate and the thickness of the oxide layer, having linear $(n=0)$, parabolic $(n=1)$ or cubic $(n=2)$ dependencies $[2,4]$.

Usually $\mathrm{n}=0$ for porous films or with very low protective properties. The oxidation process under these conditions coincides with the kinetics of the heterogeneous reaction on a clean surface. If $n=1$, then the reaction rate is determined by the diffusion of the oxidant in the oxide layer, the dependence between the diffusion coefficient and the temperature being exponential.

For some substances, including boron, the combination of different oxidation mechanisms is noticed. In such situations the reaction takes place according to several mechanisms, each of one being predominant in distinct stages of the process. For example, if initially, at normal temperatures the oxidation is parabolic $(n=1)$, later, with the increase of the temperature due to various causes (polymorphic modification, melting, vaporization of the film) the reaction speed becomes linear $(n=0)$, the whole process being defined. as a paralinear.

For metals that interact with the oxidant according to formula (1), the system of equations that describes the process of ignition of the particle (neglecting the radiant energy exchange) has the following general form [4]:

$$
\begin{gathered}
\frac{1}{6} \cdot c_{m} \cdot \rho_{m} \cdot d_{p} \cdot \frac{d T_{p}}{d t}=Q \cdot \rho_{m} \cdot \frac{d h}{d t}-\frac{\lambda \cdot N u}{d_{p}} \cdot\left(T_{p}-T_{g}\right), \\
\frac{d h}{d t}=\frac{C_{o x}^{v}}{h^{n}} \cdot k_{0} \cdot e^{-\frac{E}{R T_{p}}}
\end{gathered}
$$

$t=0 ; h=h_{0} ; T_{P}=T_{p o}$

where: $c_{m}$ is the specific calorific value of the metal, $\mathrm{J} \cdot \mathrm{K}^{-1} \cdot \mathrm{kg}^{-1}$;

$\rho_{m}$ - metal density, $\mathrm{kg} \cdot \mathrm{m}^{-3} ; d_{p}$ - particle size, $\mathrm{m} ; Q$ - thermal effect of the reaction, $\mathrm{J} \cdot \mathrm{kg}^{-1}$

$\lambda$ - thermal conductivity of the oxidant, $\mathrm{W} \cdot \mathrm{m}^{-1} \cdot{ }^{\circ} \mathrm{K}^{-1}$;

$T_{p}, T_{g}$ - temperature of the particle and oxidizing environment, ${ }^{\circ} \mathrm{K} ; t$ - time, $\mathrm{s}$,

$\mathrm{Nu}$ - Nusselt number.

The Nusselt number, the ratio between the temperature gradient of the gas oxide at the surface of single particles and the reference temperature gradient, is determined by the Ranz-Marshall criterion:

$$
N u=2+\operatorname{Re}^{0,5} \cdot \operatorname{Pr}^{0,33}
$$

where: Re, Pr are the Reynolds and Prandtl numbers under the given experimental conditions.

The Reynolds number characterizes the flow regime of the oxidant around the particle and represents the ratio between the inertial forces and the viscosity forces. The Prandtl number characterizes the physical properties of the oxidant and represents the ratio between the molecular diffusivity of the impulse and the molecular diffusivity of the heat. 
In the case of paralinear ignition reactions for $n=0, v=1$ and $B i<<1$, the ratio between the system parameters in critical ignition conditions is determined according to the theory of heterogeneous ignition [48] with the following formula:

$$
Q \cdot \rho_{m} \cdot c_{o x} \cdot \frac{E}{\lambda \cdot R} \cdot \frac{d_{p}}{N u \cdot T_{g a}^{2}} \cdot k_{0} \cdot e^{-\frac{E}{R T_{g a}}}=\frac{1}{e},
$$

where: $T_{g a}$ is the temperature of the oxidant in the place of ignition of the solid particle, in ${ }^{\circ} \mathrm{K}$;

Bi - Biot number.

When calculating the logarithm for relation (4), we obtain the following formula:

$$
\ln \left(\frac{d_{p}}{N u \cdot T_{g a}^{2}}\right)=\frac{E}{R \cdot T_{g a}}+\ln C_{1},
$$

If the experimental dependence $T_{g a}=f\left(d_{p}\right)$ is known, the graphical dependence $\lg \left(d_{p} / \mathrm{Nu} \cdot \mathrm{T}_{\mathrm{ga}}{ }^{2}\right)=F\left(T_{g a^{-1}}\right)$ will result in a line from the slope of which the activation energy can be determined according to the relation:

$$
E=2,303 \cdot R \cdot|\operatorname{tg} \alpha| \cdot r, \mathrm{~J} \cdot \mathrm{mol}^{-1}
$$

where: $R$ is the universal gas constant, $\mathrm{J} \cdot \mathrm{mol}^{-1} \cdot{ }^{\circ} \mathrm{K} ; \boldsymbol{B}$ - slope angle, degrees; $r$ - the ratio of the axle scale.

The value of the pre-exponential coefficient $k_{0}$ will be determined by substituting in formula (3) the value $E$.

If radiation heat losses (relatively larger particles) are included in the analysis, then the thermal balance of the system of equations (2) can be represented as follows:

$$
\frac{1}{6} \cdot c_{m} \cdot \rho_{m} \cdot d_{p} \cdot \frac{d T_{p}}{d t}=Q \cdot \rho_{m} \cdot \frac{d h}{d t}-\frac{\lambda \cdot N u}{d_{p}} \cdot\left(T_{p}-T_{g}\right)-\varepsilon_{p} \cdot \sigma \cdot\left(T_{p}^{4}-T_{1}^{1}\right),
$$

where: $\varepsilon_{p}$ is the emission coefficient of the particle surface;

$\sigma$ - Stefan-Boltzmann constant, $\mathrm{W} \cdot \mathrm{m}^{-2} \cdot{ }^{\circ} \mathrm{K}^{-4}$;

$T_{1}$ - temperature of the inner surface of the combustion chamber, ${ }^{\circ} \mathrm{K}$.

When taking into account the effect of thermal radiation for paralinear ignition reactions, the ratio between the parameters in the critical ignition conditions is given by the following expression:

$$
Q \cdot \rho_{m} \cdot c_{o x} \cdot \frac{E}{\lambda \cdot R} \cdot \frac{d_{p}}{N u \cdot T_{g a}^{2}} \cdot k_{0} \cdot e^{-\frac{E}{R T_{g a}}} \cdot e^{K_{R} \cdot(1-b)}=\frac{1}{e},
$$

where: $K_{R}$ is the ratio of heat loss through radiation; $b-$ ratio $\mathrm{T}_{1}{ }^{4} / \mathrm{T}_{\mathrm{ga}}{ }^{4}$.

When calculating the logarithm for relation (8), we obtain:

$$
\ln \left(\frac{d_{p}}{N u \cdot T_{g a}^{2}}\right)=\frac{E}{R \cdot T_{g a}} \cdot\left[1+(1-b) \cdot \frac{\varepsilon_{p} \cdot \sigma \cdot T_{g a}^{3}}{\lambda \cdot N u} \cdot d_{p}\right]+\ln C_{2},
$$

If the experimental dependence $T_{\mathrm{ga}}=f\left(d_{\mathrm{p}}\right)$ is known, then as a result of the graph: 


$$
\lg \left(\frac{d_{p}}{N u \cdot T_{g a}^{2}}\right)=F\left(T^{-1} \cdot\left(1+(1-b) \cdot \frac{\varepsilon_{p} \cdot \sigma \cdot T_{g a}^{3}}{\lambda \cdot N u} \cdot d_{p}\right)\right),
$$

a line will be obtained from the slope of which the activation energy $E$ will be evaluated. Consequently, from the relation (8) the value of the pre-exponential coefficient $k_{o}$ can be evaluated.

In particular, the described methodology was used to determine the kinetic constants of the ignition of single particles of crystalline boron in air and water vapor, respectively, for the following two complex heterogeneous reactions:

$$
\begin{gathered}
4 B+3 O_{2}=2 B_{2} O_{3} \quad\left(E=133400 \mathrm{~J} \cdot \mathrm{mol}^{-1} ; k_{0}=1,89 \cdot 10^{3} \mathrm{~m} \cdot \mathrm{s}^{-1}\right) \\
2 B+3 H_{2} O=B_{2} O_{3}+3 H_{2} \quad\left(E=81900 \mathrm{~J} \cdot \mathrm{mol}^{-1} ; k_{0}=2,16 \cdot 10^{3} \mathrm{~m} \cdot \mathrm{s}^{-1}\right)
\end{gathered}
$$

\section{Evaluation of kinetic parameters for the kinetic regime of combustion for solid particles.}

For the kinetic combustion regime of single particles of crystalline boron the reaction rate is determined by the following formula:

$$
R_{B}=k \cdot C_{o x}=\frac{k \cdot P_{o x}}{R \cdot T}, \mathrm{~mol} \cdot \mathrm{m}^{-2} \cdot \mathrm{s}^{-1}
$$

where: $P_{o x}$ is the partial pressure of the oxidant in the gaseous medium, $\mathrm{Pa}$.

If for the stationary combustion process, it is assumed that the density and temperature of the particle are constant as well as the combustion rate and the partial pressure of the oxidant, then for the combustion time of the particle can be calculated by the formula:

$$
t_{a r}=-\frac{1}{2 \cdot M_{B}} \cdot \int_{d_{p}}^{0} \frac{\rho_{m}}{R_{B}} \cdot d\left(d_{p}\right)=\frac{\rho_{m} \cdot R \cdot T}{2 \cdot M_{\mathrm{B}} \cdot k \cdot P_{o x}} \cdot d_{p}=k \cdot d_{p}, \mathrm{~s}
$$

For the kinetic regime the combustion time of the boron particle, measured experimentally, is proportional to the diameter of the sample.

From relation (14) the following expression is obtained:

$$
k_{0} \cdot e^{-\frac{E}{R \cdot T}}=\frac{\rho_{m} \cdot R \cdot T \cdot d_{P}}{2 \cdot M_{B} \cdot t_{a r} \cdot P_{o x}}, \mathrm{~m} \cdot \mathrm{s}^{-1}
$$

By calculating the logarithm from equation (14), the following formula is obtained:

$$
\ln \left(\frac{d_{p} \cdot T_{o x}}{t_{a r} \cdot P_{o x}}\right)=-\frac{E}{R \cdot T}-\ln \frac{R \cdot \rho_{m}}{2 \cdot M_{B}}
$$

If the experimental dependence $t_{a r}=f\left(T_{o x}\right)$ is known, then following the dependence:

$$
\lg \left(\frac{d_{p} \cdot T_{o x}}{t_{a r} \cdot P_{o x}}\right)=F\left(T_{o x}^{-1}\right)
$$

a straight line will result, from which the value of the activation energy of the complex combustion reaction in kinetic regime will be evaluated. Substituting the value $E$ in formula (15), the value of the pre-exponential coefficient $k_{0}$ can be calculated. 
For the kinetic combustion domain of the particle, the following constants of heterogeneous reactions were evaluated:

$$
\begin{aligned}
B+B_{2} O_{3} & =B O+B_{2} O_{2} \quad\left(E=89900 \mathrm{~J} \cdot \mathrm{mol}^{-1} ; k_{0}=2,38 \cdot 10^{4} \mathrm{~m} \cdot \mathrm{s}^{-1}\right) \\
B+H_{2} O & =B H O+H\left(E=62500 \mathrm{~J} \cdot \mathrm{mol}^{-1} ; k_{0}=2,48 \cdot 10^{4} \mathrm{~m} \cdot \mathrm{s}^{-1}\right)
\end{aligned}
$$

\section{Conclusions}

The ignition and combustion of single solid particles as non-isothermal methods of formal chemical kinetics contributes to obtaining unique information on the kinetics and thermodynamics of heterogeneous reactions at high temperatures, data that cannot be obtained otherwise, especially for dispersed systems.

Heterogeneous formal kinetics research is based on relatively simple experiments, with vast possibilities for varying experimental conditions.

Based on the principles of formal kinetics, which are a component of general methods of evaluating the kinetic parameters of chemical reactions, particular methods have been deducted for calculating the kinetic constants of complex reactions of ignition and combustion of single solid particles for different regimes of chemical reaction of oxidation.

The methodology for evaluating the kinetic parameters of heterogeneous oxidation reactions involves the use of some experimental data as initial data. The required experimental data is the following: the ignition temperature depending on the sample size and the combustion time of the sample depending on the oxidant temperature.

According to the theoretical formulas that describe the burning of single particles of crystalline boron, the kinetic regime of the interaction corresponds to the experimental domain in which the burning time of the sample is proportional to its size.

The procedures for evaluating the kinetic parameters of boron combustion, systematized in the paper, can be used to determine the kinetic vaporization rates of boron and boric anhydride in an inert atmosphere and the rate of gasification of anhydride in watercontaining combustion products. The experimental parameter which is measured is the durations of those processes as a dependence of the temperature of the gaseous environment.

Acknowledgements: The research was conducted within the research according to scientific contracts no. 50 „Determination of gas dynamics and kinetic parameters in the combustion of metals-containing fuels for air-powered engines”, no. 159 „Processes of combustion of metals-containing fuels” and the budget state theme no. 111 „Hardening and reconditioning of parts by thermal and thermochemical methods", running at Technical University of Moldova.

\section{References}

1. Gremyachkin V.M., Mihal'chuk M.V. Some aspects in the theory of boron combustion. In: Physicochemical kinetics in gas dynamics, 2014, pp. 1 - 8.

2. Yagodnikov D.A. Vosplamenenie i gorenie poroshkoobraznykh metallov [Ignition and combustion of powdered metals]. Moscow, Bauman MSTU Publ., 2009, 432 p. (in Russian).

3. Bakulin V.N., Dubrovkin N.F., Kotova V.N., Sorokin V.A., Frantsevich V.P., Yanovskiy L.S. Energoemkie goryuchie dlya aviatsionnykh i raketnykh dvigateley [Energy-intensive fuel for aircraft and rocket engines]. Moscow, Fizmatlit Publ., 2009, 400 p. (in Russian).

4. Hussman B., Pfitzner M. Extended combustion model for single boron particles. In: Combustion and Flame. 2010, 157, pp. $803-821$. 
5. Korotkih A.G., Arhipov V.A., Sorokin I.V., Selihova E.A. Zajiganie i gorenie visokoenergheticheskih materialov, soderjașchih aliuminii, bor i diborid aliuminia [Ignition and Combustion of high energy materials containing aluminium, boron and aluminium diboride], In: Chemical physics and mesoscopy, 2018, v. 20, No. 1, pp. 5 - 14

6. Young G., Sullivan K., Zachariah M.R., Yu K., Zachariah M. R. Combustion characteristics of boron nanoparticles. In: Combustion and Flame. 2009, v.156, No 2, pp. 322 - 333.

7. Ao W., Yang W., Han Z., Liu J., Zhou J., Cen K. Research on boron particles ignition and combustion model. In: Journal of solid rocket technology, 2012, v.35, No 3, pp.361-366, (in Chinese).

8. Jain A., Joseph K., Anthonysamy S., Gupta G.S. Kinetics of oxidation of boron powder. In: Thermochimica Acta, 2011, v.514, No. 1 - 2, pp. 67 - 73.

9. Chintersing K.A. Improving boron for combustion applications, Ph.D. Dissertations, New Jersey Institute of Technology, 2019, $337 \mathrm{p}$.

10. Potanin A.I. Polucenie keramicheskih materialov $v$ sistemah Mo-Si-B i Cr-Al-Si-B metodom samorasprostraneaiuscegosea visokotemperaturnogo sinteza [Production of ceramic materials in the Mo-Si-B and $\mathrm{Cr}-\mathrm{Al}-\mathrm{Si}-\mathrm{B}$ systems by the self-propaging metod high temperature synthesis], Ph.D. Dissertations, National Research Technological University "Moscow Institute of Steel and Alloys", 2014, 143 p.

11. Pawan K.O., Srinibas K. Boron for liquid fuel Engines-A review on synthesis, dispersion stability in liquid fuel, and combustion aspects, Progress in Aerospace Sciences, 2018, XXX, pp. 1 - 28.

12. Yagodnikov D.A., Papirin P.V., Sukhov A.V. Matematiceskaia modeli vosplamenenia odinocinoi ciastiti diborida aliuminia [A Mathematical Model of the Single Aluminium Diboride Particle Ignition], Science and Education of the Bauman MSTU, 2014, no. 12, pp. 452 - 462, (in Russian). 